\title{
Microlesions of the Inferior Olive Reduce Vestibular Modulation of Purkinje Cell Complex and Simple Spikes in Mouse Cerebellum
}

\author{
Neal H. Barmack and Vadim Yakhnitsa \\ Department of Physiology and Pharmacology, Oregon Health \& Science University, Beaverton, Oregon 97239
}

Cerebellar Purkinje cells have two distinct action potentials: complex spikes (CSs) are evoked by single climbing fibers that originate from the contralateral inferior olive. Simple spikes (SSs) are often ascribed to mossy fiber-granule cell-parallel fiber inputs to Purkinje cells. Although generally accepted, this view lacks experimental support. Vestibular stimulation independently activates primary afferent mossy fibers and tertiary afferent climbing fibers that project to the uvula-nodulus (folia 8-10). CSs and SSs normally discharge antiphasically during sinusoidal roll-tilt. When CSs increase, SSs decrease. We tested the relative independence of these pathways in mice by making electrolytic microlesions of the two inferior olivary nuclei from which vestibular climbing fibers originate; the $\beta$-nucleus and dorsomedial cell column. This reduced vestibular climbing fiber signaling to the contralateral folia $8-10$, while leaving intact vestibular primary and secondary afferent mossy fibers. We recorded from Purkinje cells and interneurons in folia $8-10$, identified by juxtacellular labeling with Neurobiotin. Microlesions of the inferior olive increased the spontaneous discharge of SSs in contralateral folia 8-10, but blocked their modulation during vestibular stimulation. The vestibularly evoked discharge of excitatory cerebellar interneurons (granule cells and unipolar brush cells) was not modified by olivary microlesions. The modulated discharge of stellate cells, but not Golgi cells, was reduced by olivary microlesions. We conclude that vestibular modulation of CSs and SSs depends on intact climbing fibers. The absence of vestibularly modulated SSs following olivary microlesions reflects the loss of climbing fiber-evoked stellate cell discharge.

\section{Introduction}

It is commonly assumed that two cerebellar afferent pathways, separately composed of mossy and climbing fibers, are responsible for modulating the discharge of the two distinct Purkinje cell action potentials: simple spikes (SSs) and complex spikes (CSs). Mossy fibers convey "on-line" information that is reflected in the high-frequency discharge of SSs. Climbing fibers convey lowfrequency "error signals" that update Purkinje cell sensitivity to parallel fibers. This conjecture of a dual afferent origin of Purkinje cell discharge has dominated discussion of cerebellar circuitry in textbooks (Ghez and Thach, 2000), scholarly reviews (Apps and Garwicz, 2005; Bloedel and Bracha, 2009), and research reports (Ebner and Bloedel, 1981; Armstrong and Edgley, 1988; Nagao, 1989; Kano et al., 1991; Lisberger et al., 1994; Walter and Khodakhah, 2006) (Fig. 1A).

The case for climbing fiber modulation of CSs is compelling. The iconic, multipeaked CS is evoked by $\sim 500$ presynaptic terminals made by a single climbing fiber as it entwines the dendrites of a Purkinje cell (Granit and Phillips, 1956; Eccles et al., 1966;

Received April 6, 2011; revised May 2, 2011; accepted May 12, 2011.

Author contributions: N.H.B. designed research; N.H.B. and V.Y. performed research; N.H.B. and V.Y. analyzed data; N.H.B. wrote the paper.

This work was supported by NIH Grants DC006668 and EY018561.

Correspondence should be addressed to Dr. Neal H. Barmack, Department of Physiology and Pharmacology, Oregon Health \& Science University, 3181 Southwest Sam Jackson Park Road, Beaverton, OR 97239. E-mail: barmackn@ohsu.edu.

DOI:10.1523/JNEUROSCI.1738-11.2011

Copyright $\odot 2011$ the authors $\quad 0270-6474 / 11 / 319824-12 \$ 15.00 / 0$
Thach, 1970; Armstrong and Edgley, 1988; Harvey and Napper, 1991). The case for mossy fiber modulation of SSs is less persuasive. A single mossy fiber has several branches that terminate over several millimeters on hundreds of granule cells whose axons ascend to the molecular layer before they bifurcate into parallel fibers and synapse on hundreds of Purkinje cells over distances of 2-7 mm (Fox et al., 1967; Palkovits et al., 1972; Brand et al., 1976) (Fig. 1A). More than $\sim 150,000$ parallel fibers course through the dendrites of each Purkinje cell (Harvey and Napper, 1991). Consequently, the attribution of SS modulation to a single or even multiple parallel fibers appears dubious.

The differential contributions of mossy and climbing fibers can be studied using a time-resolved sensory stimulus that modulates both. Vestibular stimulation effectively modulates the activity of primary vestibular afferent mossy fibers and tertiary vestibular afferent climbing fibers, both of which project to the uvula-nodulus (folia 9-10). If vestibular mossy fibers were responsible for SS modulation of Purkinje cells, then this activity should not be disrupted if the vestibular climbing fiber projection to folia 8-10 was severed leaving the mossy fiber projection intact. However, if vestibular climbing fibers modulate SSs as well as CSs, then blocking climbing fibers should reduce vestibular modulation of both CSs and SSs.

In this experiment, we blocked climbing fibers by making unilateral microlesions of the $\beta$-nucleus and dorsomedial cell column (DMCC), two subnuclei of the inferior olive (Figs. $1 B$, 2). Subsequently we recorded extracellularly the discharge of Purkinje cells and interneurons in contralateral folia 8-10 while 
A
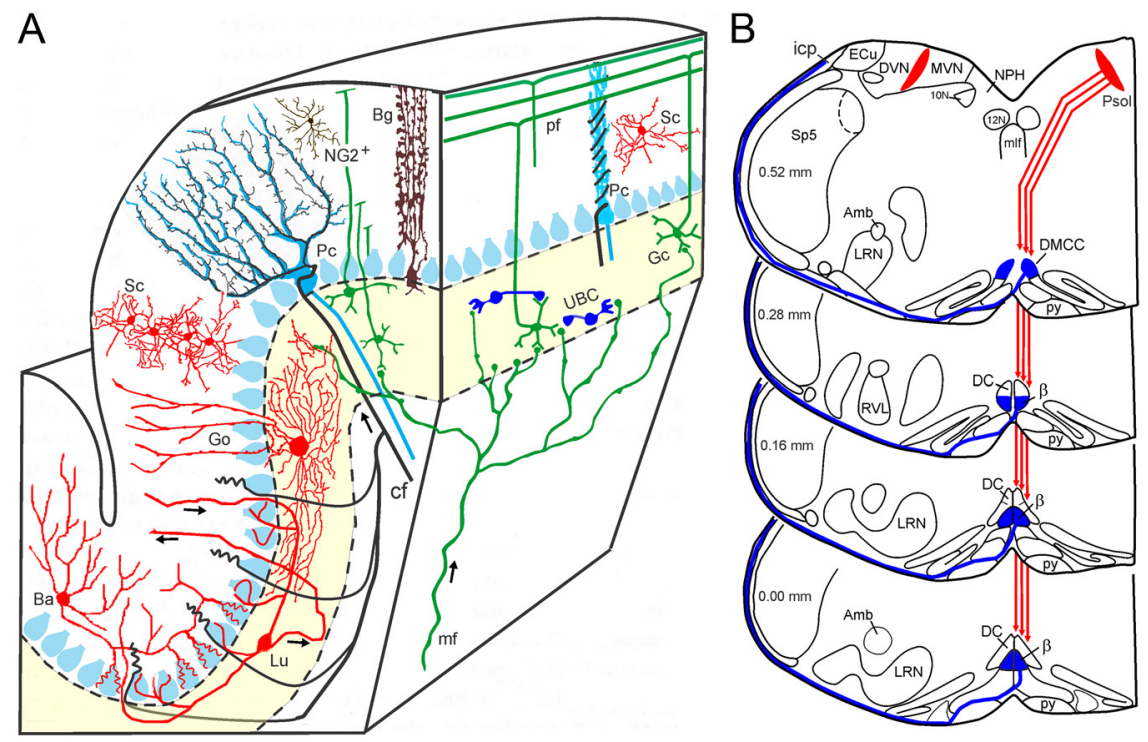

Figure 1. Cerebellar neurons and vestibular climbing fiber pathway. $A$, Diagram of cerebellar folium illustrates seven neuronal types. Inhibitory interneurons are indicated in red. The arrows indicate direction of signal propagation. $\boldsymbol{B}$, Superimposed sections of the brainstem illustrate the origins of vestibular climbing fibers to the posterior cerebellar vermis. Inhibitory projections (red) from the parasolitary nucleus (Psol) descend to the ipsilateral DMCC and $\beta$-nucleus ( $\beta$ ). Climbing fibers (blue) from these olivary nuclei ascend to the contralateral uvula and nodulus in the inferior cerebellar peduncle (icp). The numbers in the left side of each section indicate distance from the caudal pole of the $\beta$-nucleus. Abbreviations: Amb, Nucleus ambiguus; $\mathrm{Ba}$, basket cell; $\mathrm{Bg}$, Bergmann astrocyte; cf, climbing fiber; DC, dorsal cap; DVN and MVN, descending and medial vestibular nucleus; ECu, external cuneate nucleus; Gc, granule cell; Go, Golgi cell; LRN, lateral reticular nucleus; Lu, Lugaro cell; mf, mossy fiber; NPH, nucleus prepositus hypoglossi; mlf, medial longitudinal fasciculus; NG2+, glia; Pc, Purkinje cell; pf, parallel fiber; py, pyramidal tract; RVL, rostral ventrolateral reticular nucleus; $\mathrm{Sp5}$, spinal trigeminal nucleus; $\mathrm{UBC}$, unipolar brush cell; $\mathrm{SC}$, stellate cell; $10 \mathrm{~N}$, dorsal motor nucleus of the vagus; $12 \mathrm{~N}$, hypoglossal nucleus.

the mouse was sinusoidally rotated about the longitudinal axis (roll-tilt) (Yakhnitsa and Barmack, 2006; Barmack and Yakhnitsa, 2008a). Since microlesions of the inferior olive eliminate the iconic CS in Purkinje cells, rendering them electrophysiologically unidentifiable, we labeled neurons juxtacellularly with Neurobiotin and identified the recorded neurons by their classic dendritic morphology (Pinault, 1996; Simpson et al., 2005; Barmack and Yakhnitsa, 2008a). Microlesions of the inferior olive caused a loss of both vestibularly modulated CSs and SSs. The modulation of stellate inhibitory interneurons was also impaired. We attribute the impaired modulation of SSs to reduced climbing fiberevoked stellate cell inhibition of Purkinje cells.

\section{Materials and Methods}

Anesthesia and surgery. Forty-seven C57BL/6J mice (The Jackson Laboratory) (weight, 16.0-22.0 g) of either sex were anesthetized with intraperitoneal injections of ketamine $(60-70 \mathrm{mg} / \mathrm{kg})$ and xylazine $(3 \mathrm{mg} / \mathrm{kg})$. We evaluated anesthetic depth using paw withdrawal and corneal reflexes. Mice received supplemental doses of ketamine every 15-20 min. We used a servo-controlled heating pad to maintain the mouse's body temperature at $37^{\circ} \mathrm{C}$. Four small stainless-steel screws $(0-80 \times 1 / 8)$ and dental acrylic were used to anchor an inverted flat-head stainless-steel screw (4-40) between the lambda and bregma sutures. The inverted screw mated with a metal rod that maintained the head rigidly at the center of a three-axis vestibular rate table. All surgical procedures were reviewed and approved in advance by the Institutional Animal Care and Use Committee of Oregon Health \& Science University.

Retrograde transport of horseradish peroxidase. We used the retrograde transport of HRP to confirm the identity of the neurons that comprise the $\beta$-nucleus and DMCC in the mouse. We filled the tip of a micropipette with a $30 \%$ solution of HRP. The remainder of the micropipette was filled with mineral oil and connected by PE tubing to a $1 \mu \mathrm{l}$ syringe. We inserted the micropipette into folia 9 and 10 and pressure injected 20-30 $\mathrm{nl}$ of HRP. Following a $1 \mathrm{~d}$ postoperative survival, mice were deeply anesthetized with ketamine and xylazine and perfused transcardially with $0.9 \%$ saline, followed by a $2.0-2.5 \%$ paraformaldehyde and $0.2 \%$ glutaraldehyde in $0.1 \mathrm{M}$ PBS, $\mathrm{pH} 7.2$ (Rye et al., 1984; Olucha et al., 1985).

Microlesions of the $\beta$-nucleus and DMCC. Immediately after implantation of the head fixation screws, we made a unilateral microlesion of the inferior olive with the intent of destroying the $\beta$-nucleus and DMCC unilaterally. After exposing the cisterna magna below the occiput, we made a midline slit in the dura mater revealing the dorsal surface of the brainstem. We inserted a tungsten microelectrode 0.5 $\mathrm{mm}$ lateral to the midline to a depth of $1.6 \mathrm{~mm}$ at three rostrocaudal locations starting at the obex and proceeding caudally at $250 \mu \mathrm{m}$ intervals. We made two electrolytic lesions, one at the lower limit and one $100 \mu \mathrm{m}$ above this limit during each electrode penetration, using a negative current of $15-20 \mu \mathrm{A}$ for $30 \mathrm{~s}$. Thirty mice were used in acute experiments in which microelectrode recording was begun within 15 min after placement of the microlesions. Seventeen mice were used in chronic experiments during which a $1-6 \mathrm{~d}$ recovery period transpired before the mice were reanesthetized and recording was initiated.

Microelectrode recording, vestibular stimulation, and juxtacellular labeling. We made a $4 \times$ $2 \mathrm{~mm}$ opening in the occipital bone overlying cerebellar folia 7 and 8 . We slit the dura mater overlying folium 8 . A $2.5 \times 0.3 \mathrm{~mm}$ graticule with $200 \mu \mathrm{m}$ gradations was placed upon the dura mater overlying folium 7 to guide microelectrode penetrations made $\sim 220 \mu \mathrm{m}$ apart. We advanced glass micropipettes filled with $2.7 \%$ Neurobiotin in $0.5 \mathrm{M} \mathrm{NaCl}$ through folium 8 toward folium 10 with a digitally controlled hydraulic microdrive. An electrode penetration crossed as many as six layers of Purkinje cells from the dorsal surface of folium 8 to the ventral surface of folium 10 .

Mice were placed in a three axis rate table with the head centered on the rotation axes. They were sinusoidally roll-tilted about the longitudinal axis at $0.2 \mathrm{~Hz}, \pm 10^{\circ}$.

We labeled neurons juxtacellularly by electroporating the plasma membrane through the micropipette and ejecting Neurobiotin using positive current pulses (1-5 nA, $300 \mathrm{~ms}, 50 \%$ duty cycle) for 1-3 min (Pinault, 1996; Simpson et al., 2005; Holtzman et al., 2006a; Barmack and Yakhnitsa, 2008a). We established a "loose patch" by increasing current amplitude until the discharge frequency of the recorded neuron was entrained by positive current pulses.

Data analysis. We analyzed action potentials using "Spike2 spike shape recognition” software (Cambridge Electronic Design). We digitized and stored recordings for off-line analysis, in which we used fitted templates of action potential waveforms to discriminate action potentials. The software also displayed data in peristimulus histograms, constructed by storing interspike intervals (ISIs) in 1 of 180 bins. Bin width was $27.7 \mathrm{~ms}$. Spike frequency for each bin was computed from the reciprocal of the mean ISI as follows: mean rate $=1 /(\Sigma$ ISIs in bin $) /($ bin spike count $)$. This method is preferable to simply adding spike occurrences to bins while discarding information concerning interspike intervals, particularly for the low numbers of spike occurrences of CSs (Barmack and Yakhnitsa, 2003). Peristimulus histograms included $10-50$ cycles of vestibular stimulation at $0.2 \mathrm{~Hz}$ and were fitted with a cosine function by a least-squares method. The phase of responses relative to head position was derived from the fitted cosine function: $Y(t)=\mathrm{DM} \cos (2 \pi f t+\varphi)+B$, where DM is depth of modulation, $B$ is average discharge rate, $\varphi$ is phase relative to head position, and $f$ is stimulus frequency. 

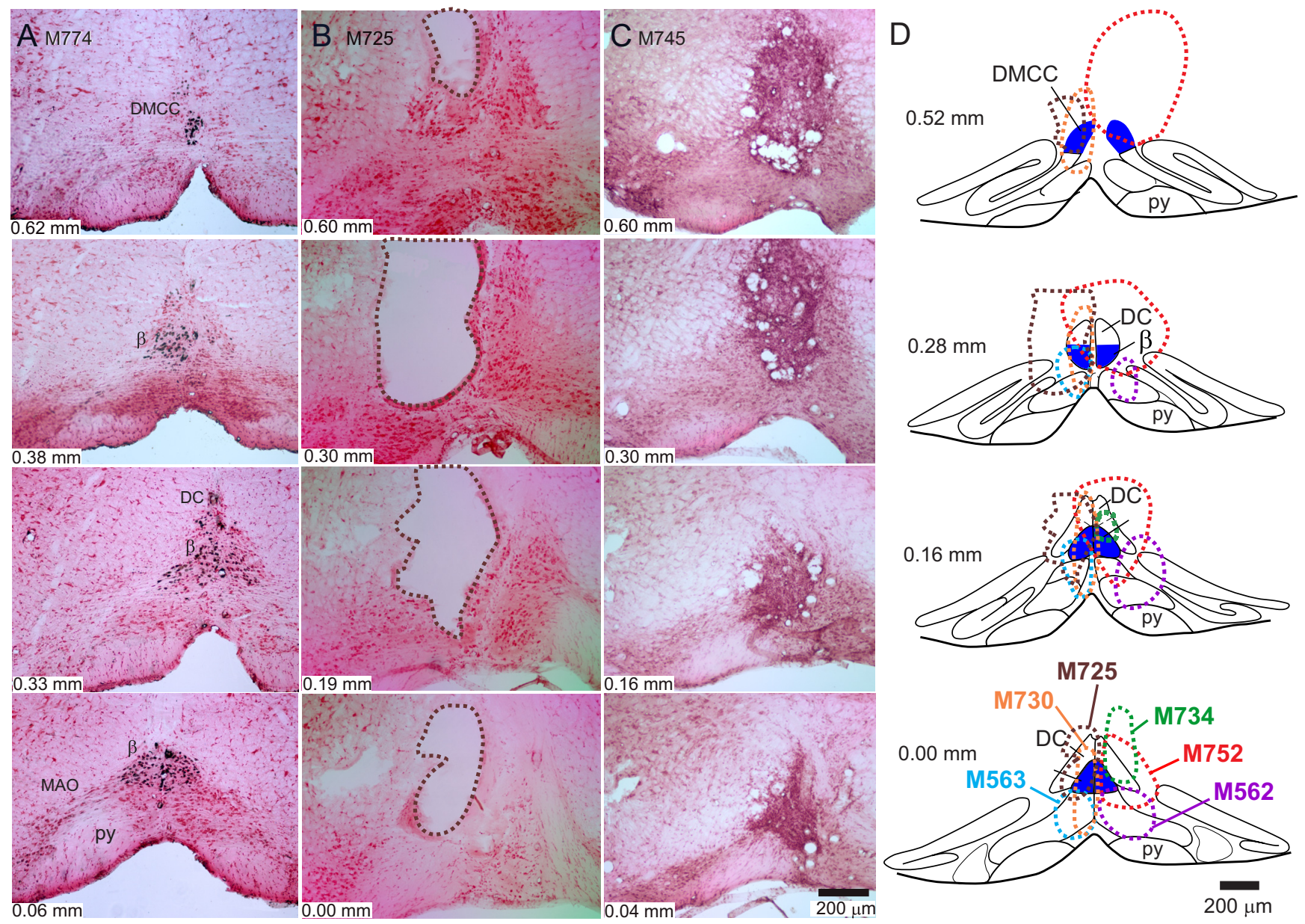

Figure 2. Microlesions of the $\beta$-nucleus and DMCC. $A$, Retrograde transport of HRP injected into the right folia $9-10$ labeled neurons in an axis extending from the caudal $\beta$-nucleus to the most rostral DMCC. $\boldsymbol{B}, \boldsymbol{C}$, Photomicrographs document the extent of two unilateral electrolytic microlesions in the left inferior olive, arrayed in separate columns from caudal (bottom) to rostral (top). $\boldsymbol{B}$, Microlesion M725 was one of the three largest and was made acutely on the same day as juxtacellular recordings from the cerebellum were performed. It destroyed most of the left $\beta$-nucleus and DMCC. C, Microlesion M745 was made chronically $96 \mathrm{~h}$ before juxtacellular recording. It destroyed most of the $\beta$-nucleus and DMCC. The site of the microlesion is filled in with microglia. D, Six microlesions are illustrated schematically with dashed lines. The three largest microlesions for all experiments, M725 (brown), M730 (orange), and M752 (red), destroyed most of the $\beta$-nucleus and DMCC. The three smallest microlesions for all experiments, M734 (green), M562 (violet), and M563 (light blue), damaged less than one-half of the $\beta$-nucleus and left the DMCC intact. The numbers to the left of each set of panels indicate distance from caudal pole of the $\beta$-nucleus. Abbreviations: $\beta$, $\beta$-Nucleus; DC, dorsal cap; MA0, medial accessory olive; py, pyramidal tract.

We classified a neuron as "vestibularly responsive" if the second harmonic was $<50 \%$ of the fundamental, and the signal/noise of the fundamental frequency divided by the average of all frequency components above the second harmonic was $>1.5$. This second criterion was especially applicable to neurons with saturated or "cutoff" responses (Schor et al., 1984). For each population of recorded cells, we present data in a polar plot. The length of the resultant vector in these plots indicates mean $\mathrm{DM}$ and is plotted logarithmically. The vector angle indicates the mean phase $(\varphi)$ with respect to head position during ipsilateral roll-tilt. A phase of $0^{\circ}$ indicates that the recorded neuron fired in phase with ipsilateral roll-tilt. A phase of $90^{\circ}$ indicates that the discharge was in phase with ipsilateral velocity, and so on.

We used a two-tailed $F$ statistic to test for differences between resultant vectors in polar plots of two cell populations (Zar, 1984). We used a two-tailed $\chi^{2}$ statistic to compare frequency distributions of cells that were driven or not driven by vestibular stimulation. We used a two-tailed Student's $t$ statistic to compare spontaneous discharge frequencies. Unless noted otherwise, data are presented as mean \pm SD.

Histology. After juxtacellularly labeling recorded neurons, we waited $45 \mathrm{~min}$ before deeply anesthetizing the mouse and perfusing it transcardially with $20 \mathrm{ml}$ of $0.9 \% \mathrm{NaCl}$, followed by $100 \mathrm{ml}$ of $4 \%$ paraformaldehyde and $0.1 \%$ picric acid in $0.1 \mathrm{M}$ PBS, $\mathrm{pH} 7.4$. We removed the brain and kept it in the fixation solution overnight at $4^{\circ} \mathrm{C}$. After cryoprotection with a series of graded sucrose solutions, the cerebellum was detached from the brainstem and blocked. It was frozen in isopentane, cooled by $\mathrm{CO}_{2}$, and cut sagittally on a cryostat at $40 \mu \mathrm{m}$. Free-floating sections were processed according to a biotin/streptavidin-HRP protocol (Barmack and Yakhnitsa, 2008a). For mice with microlesions of the inferior olive, we prepared transverse cryostat sections of the brainstem ( $30 \mu \mathrm{m}$ thick) through the inferior olive and stained them with neutral red. The extent of each microlesion was superimposed onto a schematic of the inferior olive (see Fig. 2).

Photomicroscopy. We photographed Neurobiotin-labeled neurons with a digital camera, obtaining images at three different focal planes for each neuron. We combined these images using a digital image fusion program (Media Cybernetics) to obtain extended depth of field.

\section{Results}

\section{Targeting the $\beta$-nucleus and DMCC in the mouse}

We pressure-injected HRP into folia $9-10$ to retrogradely label neurons in the $\beta$-nucleus and DMCC (Fig. 2A). HRP-labeled neurons were confined to a midline axis that extended from the most caudal aspect of the $\beta$-nucleus $\sim 0.6 \mathrm{~mm}$ to the most rostral aspect of the DMCC. We made electrolytic lesions along this axis and attempted to limit damage to other olivary subnuclei and other brainstem nuclei. Examples of acute and chronic microlesions indicate modest success in achieving this objective (Fig. 
A

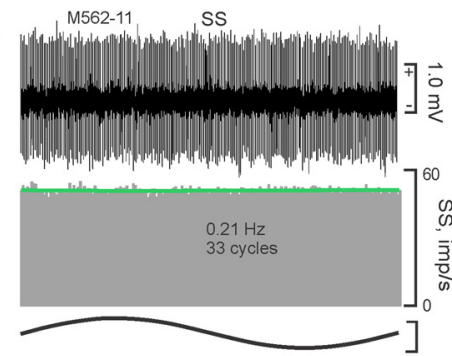

B
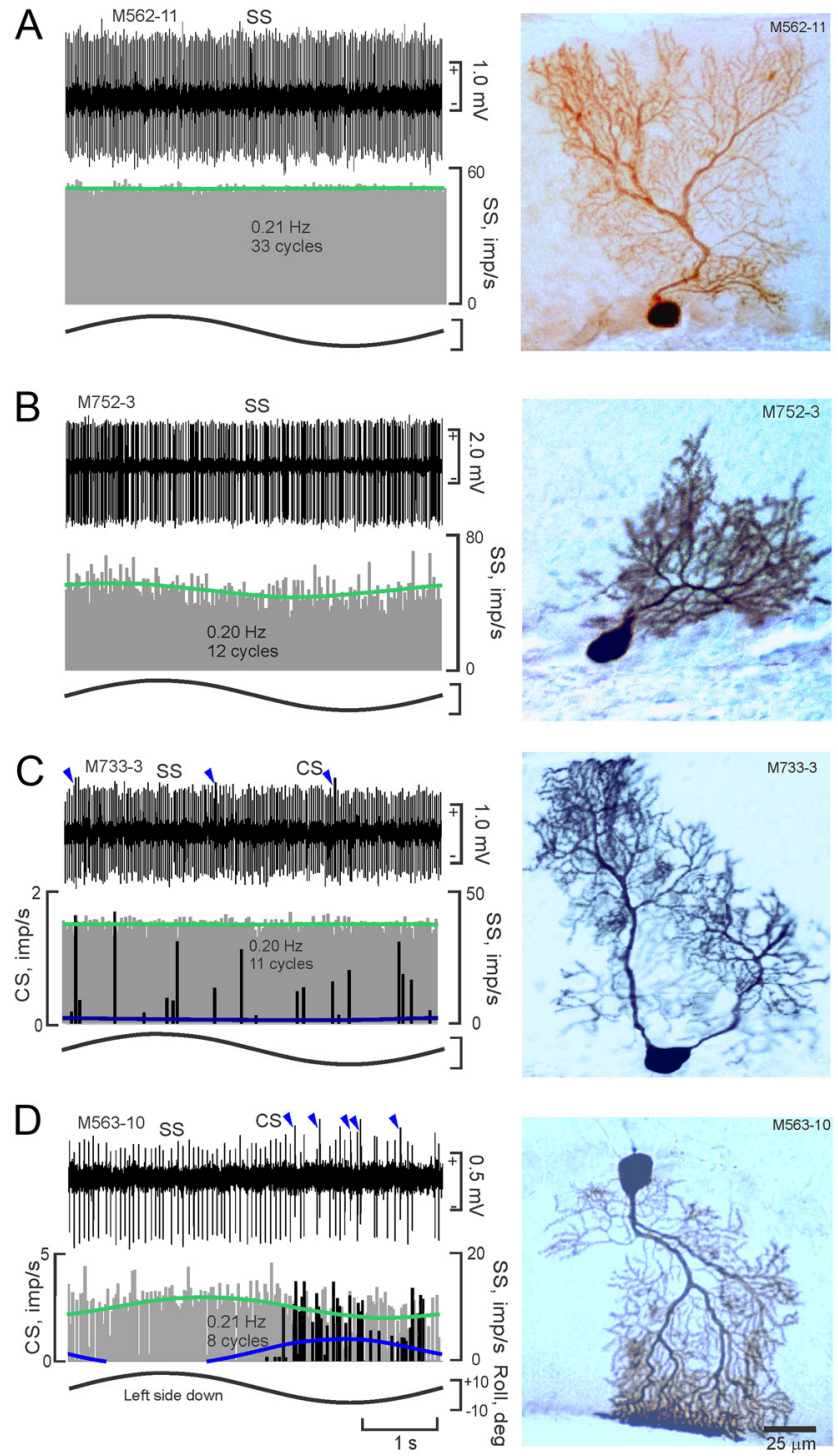

Figure 3. Vestibular modulation of SSs in Purkinje cells with and without CSs. We recorded vestibularly modulated activity of Purkinje cells in folia 8-10 contralateral to olivary microlesions. A, Purkinje cell M562-11, located in left folia 9, lacked a $C S$ after a microlesion was made in the right inferior olive. Its SSs were not modulated by sinusoidal roll-tilt. The second trace is a peristimulus histogram for SSS, fitted with a cosine function (green). B, Purkinje cell M752-3, located in left folium 10, lacked a CS, after a microlesion in the right inferior olive. SSs were weakly modulated during ipsilateral roll-tilt. C, Purkinje cell M733-3, located in right folium 9, retained both CSs and SSS, but neither was modulated. D, Purkinje cell M563-10, located in right folium 9, retained both a modulated CS and SSs following an incomplete microlesion of the left inferior olive. CSs are indicated with blue arrowheads. The peristimulus histogram indicates modulation of CSs (black bars) and SSs (gray bars). CSs and SSs were fitted with a cosine functions (CSs, blue; SSs, green). The scale bar in $\boldsymbol{D}$ applies to other panels.

$2 B, C)$. The three largest microlesions, M725, M730, and M752, destroyed $>90 \%$ of the $\beta$-nucleus and DMCC. The three smallest microlesions, M724, M562, and M563, destroyed $<50 \%$ of the targeted olivary neurons, leaving the rostral DMCC intact.

\section{Microlesions of the inferior olive reduce vestibular modulation of CSs and SSs}

Microlesions of the inferior olive had four consequences on Purkinje cell CSs in contralateral folia 8-10. First, the microlesion caused a complete loss of CSs and a loss of vestibular modulation of SSs (Fig. 3A). Second, the microlesion caused a complete loss of CSs, but left a residual vestibular response of SSs (Fig. 3B).
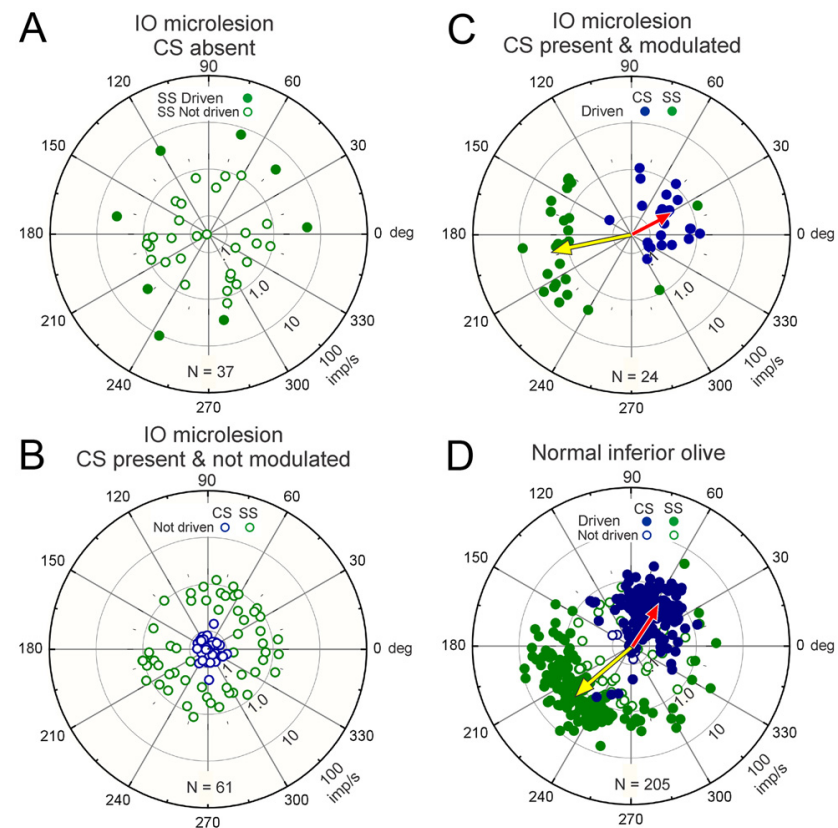

Figure 4. Polar plots of vestibularly modulated CSs and SSs from four populations of Purkinje cells. $\boldsymbol{A}$, Thirty-seven Purkinje cells contralateral to an inferior olivary microlesion had no CS. In 29 of these, SSs were not modulated by roll-tilt (open green circles). Eight cells had modulated SSs (filled green circles) distributed in all four quadrants. $\boldsymbol{B}$, Sixty-one Purkinje contralateral to the microlesions retained spontaneous (Ss that were not modulated during sinusoidal roll-tilt (open blue circles). None of these Purkinje cells had modulated SSs (open green circles). C, Twenty-four Purkinje cells contralateral to olivary microlesions had vestibularly modulated CSs (filled blue circles) and SSs (filled green circles), although the DM and phase of the resultant vectors differed from the responses of Purkinje cells recorded in mice with intact inferior olives. D, A total of 205 Purkinje cells previously recorded in mice with intact inferior olives confirms that $<10 \%$ of CSs and $20 \%$ of SSs were unresponsive to vestibular roll-tilt.

Third, the microlesion left intact CSs, but these were no longer modulated by vestibular stimulation (Fig. $3 C$ ). Fourth, the microlesion left intact both CSs and SSs and both of these were responsive to vestibular stimulation (Fig. 3D). We classified a CSs or SSs as vestibularly responsive if the second harmonic was $<50 \%$ of the fundamental and the signal/noise of the fundamental frequency divided by the average of all frequency components above the second harmonic was $>1.5$.

Microlesions abolished CSs in 37 Purkinje cells. In 29 of these, Purkinje cells vestibular modulation of SSs was absent (Figs. $3 A, B, 4 A$ ). In eight of these Purkinje cells lacking CSs, residual modulation of SSs remained but had no consistent phase with respect to the sinusoidal vestibular stimulus (Fig. $4 A$, filled green circles). The lack of modulation of SSs in Purkinje cells without CSs contrasts to that observed in normal mice in which the SSs in $82 \%$ of Purkinje cells were vestibularly modulated (Fig. $4 D$, filled green circles).

In 61 Purkinje cells, unilateral microlesions of the contralateral $\beta$-nucleus and DMCC failed to eliminate spontaneous CSs, although these CSs were not vestibularly modulated (Fig. $4 B$, open blue circles). In these cases, incomplete microlesions blocked descending input to neurons in the $\beta$-nucleus and DMCC, but left many inferior olivary neurons intact. In none of these 61 Purkinje cells were SSs modulated by sinusoidal roll-tilt (Fig. 4 B, open green circles). The lack of any SS modulation in Purkinje cells with intact climbing fibers, but unmodulated CSs differs from that of 8 of 37 Purkinje cells in which CS were completely absent (Fig. $4 \mathrm{~A}$, filled green circles). 
In 24 Purkinje cells, incomplete olivary microlesions left intact CSs whose discharge was modulated during sinusoidal rolltilt (Fig. 4C). In 23 of 24 of these Purkinje cells, the discharge of CSs increased and that of 22 of 24 SSs decreased during ipsilateral roll-tilt. The discharges of CSs and SSs evoked in mice with these incomplete microlesions were qualitatively similar to the discharges evoked in normal mice. However, vestibularly evoked discharges of CSs and SSs in the two groups were quantitatively different (Fig. 4C,D). In normal mice, sinusoidal roll-tilt modulated the discharge of CSs with a DM of $0.4 \mathrm{imp} / \mathrm{s}$ with a phase of $58^{\circ}$ (Fig. $4 D$, red arrow) and SSs had a DM of $1.8 \mathrm{imp} / \mathrm{s}$ with a phase of $221^{\circ}$ (Fig. $4 D$, yellow arrow). In mice with olivary microlesions, CSs had a DM of $0.4 \mathrm{imp} / \mathrm{s}$ with a phase of $29^{\circ}$ and SSs had a DM of $2.2 \mathrm{imp} / \mathrm{s}$ with a phase of $192^{\circ}$ (Fig. 4C). These differences were significant $(F$ test, $p<0.01)$. After a microlesion, even when a Purkinje cell retained an intact climbing fiber input, its discharge was influenced by the absence of other functional climbing fibers that may have terminated nearby and influence Purkinje cell discharge through interneuronal inhibition.

\section{Acute and chronic unilateral microlesions of $\beta$-nucleus and DMCC decrease vestibular modulation of SSs}

The effects of unilateral microlesions of the $\beta$-nucleus and DMCC could be detected in the open-field behavior of mice at various times after the microlesions were placed. Four hours postoperatively, mice evinced a tendency to tilt, turn, and fall toward the contralateral side. These behavioral effects have been previously documented in the cat (Horn et al., 2010). Within $2 \mathrm{~d}$, these postural disturbances were compensated.

The induction and compensation of postural disturbances by unilateral inferior olivary microlesions suggested that electrophysiological analysis of the chronic effects of inferior olivary microlesions might further illuminate the role of the inferior olive in cerebellar function. Consequently, we examined possible chronic changes in Purkinje cell discharge related to adaptation to unilateral microlesions of the $\beta$-nucleus and DMCC.

Initially, we compared the effects of acute and chronic olivary microlesions on the DM and phase of CSs and SSs evoked by sinusoidal roll-tilt. These were similar in mice with acute microlesions and in mice from which recordings were obtained on average $\sim 4 \mathrm{~d}$ after the microlesions ( $F$ test, $p>0.25$ ). Accordingly, we combined data from both types of experiments in polar plots (Fig. 4).

\section{Spontaneous SSs increase after microlesions of the inferior olive}

We subdivided Purkinje cells into three categories based on CSs:

(1) CSs were present and modulated by vestibular stimulation;

(2) CSs were present, but unmodulated; and (3) CSs were abolished (Fig. 5). When a CS was present, the spontaneous discharge of SSs was increased in chronic, but not acute mice. When a CS was absent, the discharges of SSs were increased in both chronic and acute mice (Fig. 5B; $t$ test, $p<0.0001$ ).

Increases in spontaneous SS discharge were reciprocal with decreases in CS discharge. In some mice with acute olivary microlesions, the frequency of CSs increased relative to the frequency of CSs in normal mice (Fig. 5A). These increases could be accounted for by the dorsal location of the microlesions. Such microlesions disrupted descending inhibitory connections from the parasolitary nucleus (Psol) to the $\beta$-nucleus and DMCC, thereby removing descending inhibition from olivary neurons that remained intact (Fig. $1 B$ ). We also recorded from several Purkinje cells that evinced high-
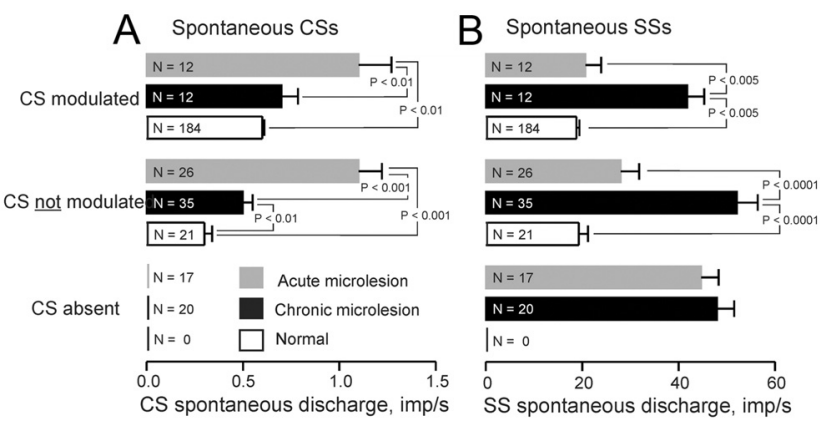

Figure 5. Spontaneous discharge of CSs and SSs after microlesions of inferior olive. Spontaneous activity of CSs and SSs was measured in normal mice, mice with acute microlesions of the contralateral inferior olive, and mice with chronic microlesions. Purkinje cells were further subdivided into three groups: (1)CSs were vestibularly modulated; (2) CSs were present, but not modulated; and (3) CSs were absent. $\boldsymbol{A}$, The discharge of CSs was increased in mice with acute microlesions relative to the discharge of CSs in both normal mice and in mice with chronic microlesions. This increase was maintained in mice with CSs that were modulated and in mice with CSs that were unmodulated. $\boldsymbol{B}$, The discharge of SSs increased in mice with chronic microlesions relative to mice with acute microlesions and normal mice. This increase applied to mice in which the CSs were modulated by vestibular stimulation and to mice in which CSs were present, but not modulated. When the CS was absent, the spontaneous activity of SSs was not different for mice with acute or chronic microlesions. Both were increased with respect to the discharge of SSs in normal mice. The $p$ value for each $t$ test is indicated for bar graphs connected with thin lines. The number of each cell type is indicated within the bars. Error bars indicate SEM.

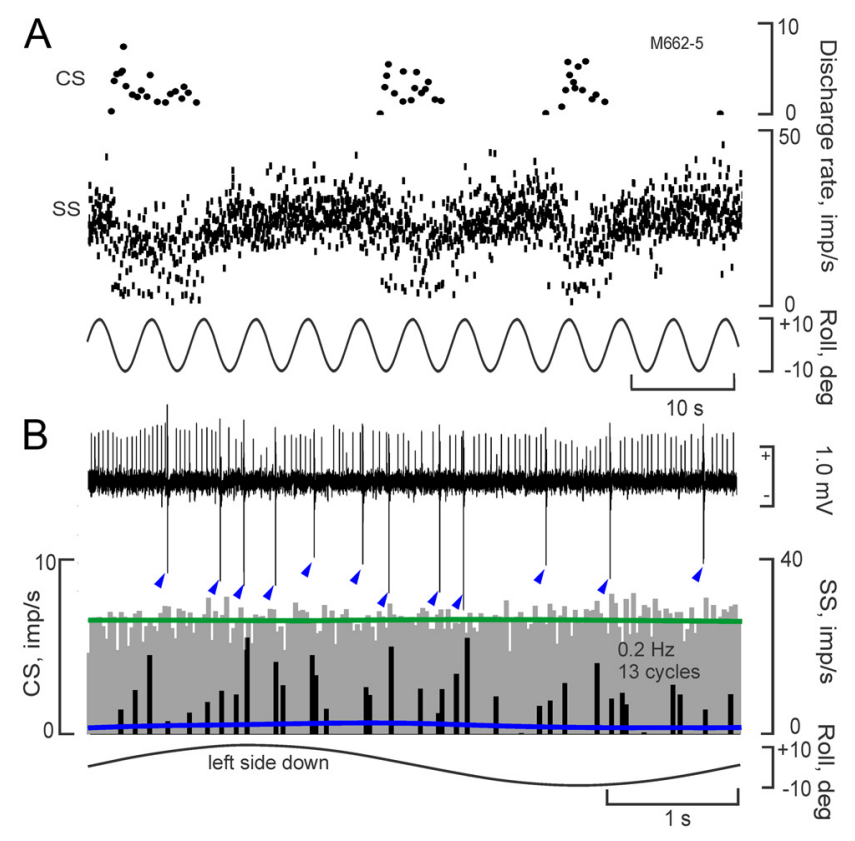

Figure 6. Microlesions of $\beta$-nucleus and DMCC induce bursting of CSs and SSs. Microlesions of the inferior olive were always incomplete. Consequently, some contralateral Purkinje cells retained intact climbing fiber projections, but abnormal activity. In such cases, CSs and SSs often evinced high frequency bursting of both CSs and SSs. A, Instantaneous discharge rates illustrate antiphasic bursting of both CSs and SSs. The top trace shows bursts of $C S s$ that exceeded $8 \mathrm{imp} / \mathrm{s}$. The middle trace shows SS bursting. The bottom trace indicates vestibular roll-tilt. $\boldsymbol{B}$, The top trace shows bursting of both CSs (blue arrowheads) and SSs. Peristimulus histogram indicates that bursting was unrelated to vestibular stimulation. CSs and SSs were fitted with cosine functions (CS, blue; SS, green).

frequency antiphasic bursting of CSs and SSs. During such bursts, CSs often attained frequencies of $\sim 8 \mathrm{imp} / \mathrm{s}$, higher than any observed in normal mice or in mice with chronic olivary microlesions. These aberrant discharges were not entrained by vestibular stimulation (Fig. 6). 
A P cells in normal folia 8-10

B P cells after unilateral microlesion of I.O.

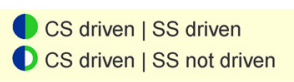

C CS not driven I SS driven

O cS not driven | SS not driven

CS absent | SS driven

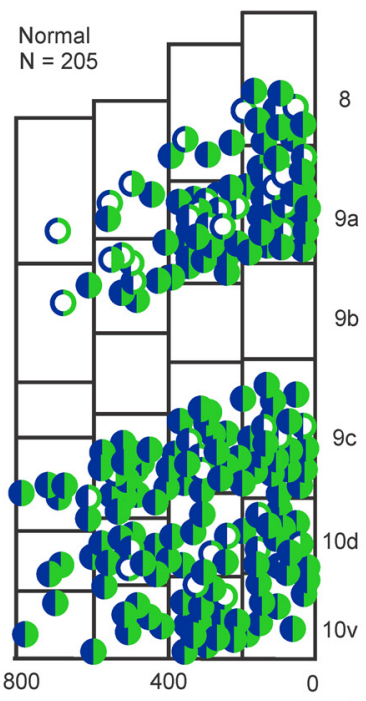

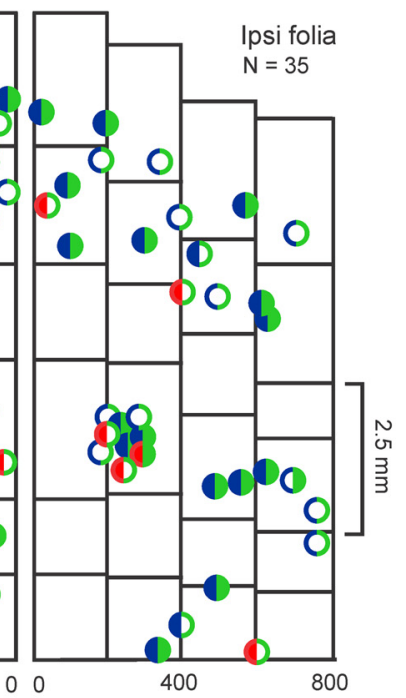

Distance from midline, $\mu \mathrm{m}$

Figure 7. Topographic distribution of recorded Purkinje cells in normal mice and mice with microlesions of the inferior olive. Two-dimensional maps were made of folia $8-10$. The locations of all recorded Purkinje cells were plotted on these maps. A, A total of 205 Purkinje cells was previously recorded from normal mice. The symbols indicate responsiveness of CSs and SSs to roll-tilt at $0.2 \mathrm{~Hz}$. CSs in 184 Purkinje cells responded to ipsilateral side-down rotation. In 162 of 184 Purkinje cells with responsive $C S s$, SSs responded to contralateral side-down rotation. $\boldsymbol{B}$, A total of 122 Purkinje cells was recorded in folia $8-10$ after a contralateral microlesion was made in the $\beta$-nucleus and DMCC. CSs were totally abolished in 37 Purkinje cells. SSs were present, but unmodulated in 29 of these cells. In eight others, the discharge of SSs increased during vestibular stimulation, but with a broad range of phases. In 61 Purkinje cells, CSs and SSs were present, but unresponsive to vestibular roll-tilt. In 35 Purkinje cells recorded from the ipsilateral folia, 6 lacked CSs. In only one of these cells was the discharge of the SSs modulated. In 11 Purkinje cells, the vestibularly modulated discharge of CSs was absent. The SS discharge of 10 of these cells was also not modulated by vestibular stimulation. In 18 Purkinje cells, the discharge of CSs was modulated. In these cells, the discharges of 16 SSs were also modulated.

\section{Topography of Purkinje cells with decreased vestibularly responsive CSs and SSs}

In 184 of 205 of Purkinje cells recorded from normal mice, the discharge of CSs increased in phase with ipsilateral roll-tilt (Barmack and Yakhnitsa, 2003, 2008b). In 162 of 184 Purkinje cells, the discharge of SSs decreased during ipsilateral roll-tilt (Fig. $4 D$ ). These vestibularly responsive Purkinje cells were distributed in folia $8-10$ with a tendency for folia 8 and 9 a to have more unresponsive Purkinje cells (Fig. 7A, open circles).

By contrast, in 98 of 122 Purkinje cells recorded in folia 8-10, contralateral to microlesions of the inferior olive, CSs were either absent or not vestibularly modulated (Fig. 7B). In 90 of 98 of these Purkinje cells, the SSs were also not modulated by vestibular stimulation. In the 24 Purkinje cells with modulated CSs, all had modulated SSs. The DM and phase of the modulation were different from those we observed for normal Purkinje cells (see above).

Although we mostly restricted microlesions to the intended unilateral targets, they inevitably destroyed climbing fiber axons that originated from the contralateral inferior olive and crossed through the area of the microlesion. This loss of climbing fibers was reflected in an increased number of Purkinje cells in ipsilateral folia 8-10 that lacked vestibularly modulated CSs and SSs (Fig. 7B).

\section{Unilateral microlesions have limited influence on contralateral excitatory interneurons}

The absence of SS modulation following loss of climbing fiber input prompted us to examine how olivary microlesions influ- enced the discharge of cerebellar interneurons. In this effort, we were hindered by the absence of an electrophysiological marker, such as the CS in Purkinje cells, that could identify an intact climbing fiber input. Consequently, we could not know whether a particular interneuron was in a region of the contralateral folia in which functional climbing fibers remained. Nor could we know whether an interneuron normally received inputs from one or several climbing fibers.

We recorded from only two basket and two Lugaro cells, too few to include in this analysis. We recorded from greater numbers of four other interneurons-granule, unipolar brush, Golgi, and stellate cellsand proceeded with an analysis of their activity following olivary microlesions.

Granule cells retained their vestibularly modulated activity. In one experiment, we recorded simultaneously from a granule cell and a Purkinje cell. The action potentials of these two neurons could be distinguished easily (Fig. 8A). We juxtacellularly labeled both cells (Fig. $8 \mathrm{~B}$ ). The discharge of CSs and the granule cell increased during ipsilateral roll-tilt. The discharge of SSs increased during contralateral roll-tilt. Thus, the granule cell discharged out of phase with respect to SS. A polar plot illustrates the DM and phase for each of the three responses (Fig. 8B). Synaptic excitation from sources other than ascending axon or parallel fiber of the subjacent granule cell contributed to the modulation of SSs in the Purkinje cell.

As in the case of Purkinje cells, we measured three parameters of granule cell discharge in mice with microlesions of the inferior olive and in mice with intact inferior olives. First, microlesions increased the spontaneous discharges of granule cells, but not significantly with respect to normal mice $(14.3 \pm 14.9$ vs $3.3 \pm 3.8$ $\mathrm{imp} / \mathrm{s} ; t$ test, $p>0.2)$. Second, the percentage of granule cells that responded to vestibular stimulation in mice with microlesions was reduced, but not significantly (66 vs $72 \% ; \chi^{2}$ test, $p>0.8$ ). Third, the resultant DMs and phases for mice with microlesions and those in mice with intact inferior olives were not different $(F$ test, $p>0.2$ ) (Fig. 9A).

We made similar measurements from unipolar brush cells (UBCs). The spontaneous discharge of UBCs in mice with olivary microlesions increased relative to those of normal mice, but not significantly $(17.8 \pm 15$ vs $10.0 \pm 11.6 \mathrm{imp} / \mathrm{s} ; t$ test, $p>0.1)$. The percentage of UBCs in mice with microlesions that were responsive to vestibular stimulation decreased with respect to UBCs in normal mice, but again not significantly ( 75 vs $90 \% ; \chi^{2}$ test, $p>$ $0.2)$. The resultant DM and phase for UBCs in both groups was not different $(F$ test, $p>0.5)$ (Fig. $9 B)$.

\section{Effects of microlesions of the inferior olive on vestibular modulation of Golgi cells}

We recorded from 22 Golgi cells in mice with microlesions of the inferior olive. Fifteen of these cells were modulated during sinusoidal roll-tilt. In one experiment, we recorded simultaneously 
from a Golgi and Purkinje cell (Fig. $10 A, B)$. In this instance, the discharges of CSs and SSs in the Purkinje cell, as well as the discharges of the Golgi cell were not modulated by sinusoidal roll-tilt. More generally, the percentage of Golgi cells responsive to vestibular stimulation in mice with microlesions was comparable with that of normal mice (70 vs 78\%; $\chi^{2}$ test, $p>0.4$ ) (Fig. 10C,D). The resultant DM and phase for Golgi cells in both groups were not different ( $F$ test, $p>0.5$ ). The spontaneous discharges of Golgi cells in mice with microlesions increased with respect to that of Golgi cells in normal mice, but this increase was not statistically significant $(10.4 \pm 18.4 \mathrm{vs} 2.7 \pm 2.1 \mathrm{imp} / \mathrm{s} ; t$ test, $p>0.06)$. The large variability in the Golgi cell population in mice with microlesions could be accounted for by three Golgi cells whose discharges exceeded 40 $\mathrm{imp} / \mathrm{s}$. This skewed the mean discharge of Golgi cells relative to the normal population. The median spontaneous discharge for Golgi cells in mice with olivary microlesions was 2.8 vs $2.5 \mathrm{imp} / \mathrm{s}$ in mice with intact inferior olives.

\section{Microlesions of the inferior olive reduce vestibular modulation of stellate cells}

We recorded from 15 stellate cells in folia 8-10 contralateral to olivary microlesions (Fig. 11 A,B). Only four of these stellate cells were modulated by vestibular roll-tilt. In mice with intact inferior olives 36 of 47 stellate cells were responsive to vestibular roll-tilt, responding with a phase lead of $13^{\circ}$ to ipsilateral roll-tilt. The percentage of stellate cells responsive to vestibular stimulation in mice with microlesions was significantly reduced (26 vs $77 \% ; \chi^{2}$ test, $p<0.001)$. The resultant vector in the polar plots of stellate cells in mice with microlesions had a DM of $0.9 \mathrm{imp} / \mathrm{s}$ with a phase of $154^{\circ}$ (Fig. $11 \mathrm{D}$ ). In normal mice, stellate cells had a DM of $1.65 \mathrm{imp} / \mathrm{s}$ with a phase of $13^{\circ}$ (Fig. 11C). The difference between the resultant vectors of these two populations was significant ( $F$ test, $p<0.01$ ). In normal mice, the stellate cell population responded to ipsilateral roll-tilt. In mice with microlesions of the inferior olive, resultant vector was shifted by $141^{\circ}$. The spontaneous discharge of stellate cells was elevated with respect to the discharge of stellate cells in normal mice. However, this difference was not significant $(20.2 \pm 25.3$ vs $10.0 \pm 10.9 \mathrm{imp} / \mathrm{s} ; t$ test, $p>0.2)$.

The change in evoked stellate cell activity indicates the importance of stellate cells in cerebellar cortical function. The importance of stellate cells is underscored by their abundance. We counted all stellate cells within a rectangular area encompassed by 10 Purkinje cells, making no attempt to correct for tissue shrinkage. In the rabbit cerebellum, the mean number of stellate cells/ Purkinje cell was $23 \pm 3$. In the mouse cerebellum, it was $14 \pm 2$. In human cerebellum, this ratio is $\sim 55$ (Korbo et al., 1993). These data suggest that climbing fiber-activated stellate cell inhibition of Purkinje cells could account for the antiphasic modulation of CSs and SSs. Conversely, in mice with microlesions of the inferior olive, reduced stellate cell discharge could account for decreased modulation of SSs.
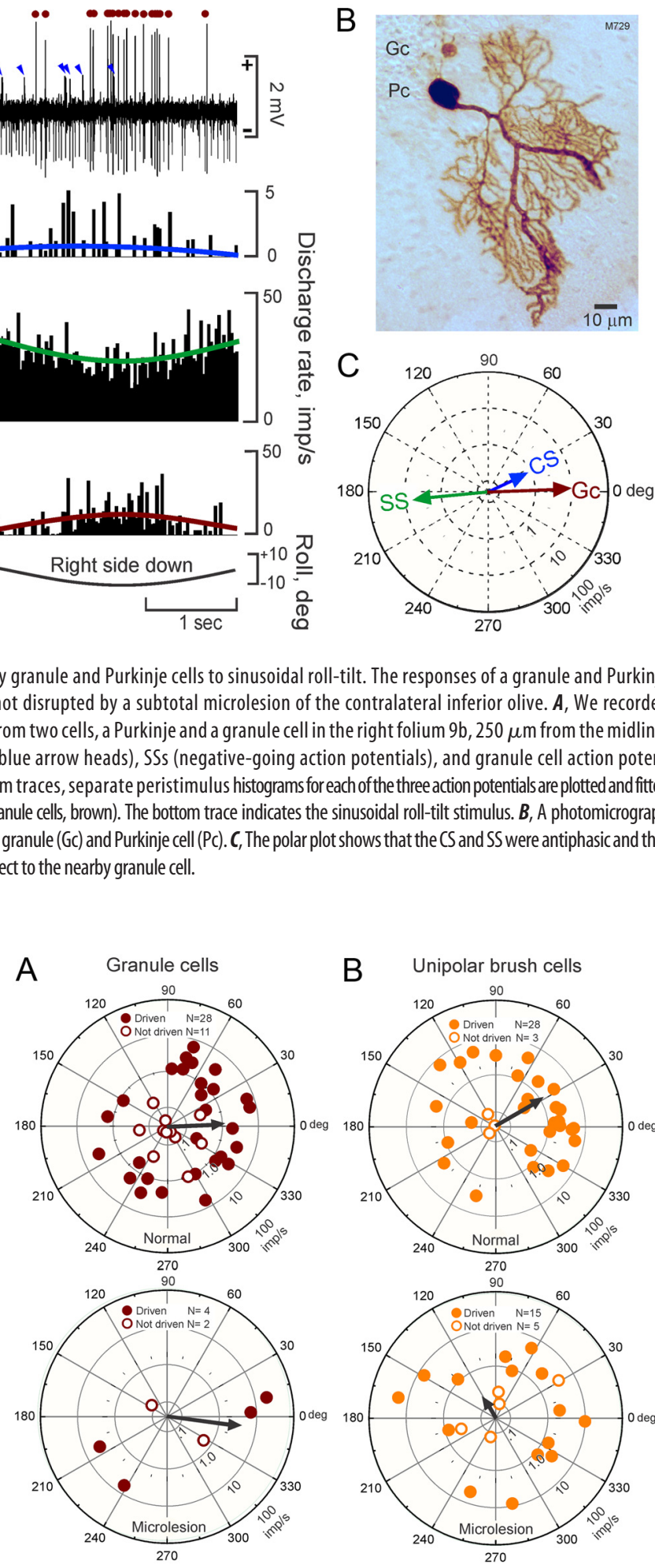

Figure 8. Responses of nearby granule and Purkinje cells to sinusoidal roll-tilt. The responses of a granule and Purkinje cell to sinusoidal roll-tilt were not disrupted by a subtotal microlesion of the contralateral inferior olive. $\boldsymbol{A}$, We recorde with cosines (CSs, blue; SSs, green; granule cells, brown). The bottom trace indicates the sinusoidal roll-tilt stimulus. $\boldsymbol{B}$, A photomicrograp the SS was also antiphasic with respect to the nearby granule cell. 

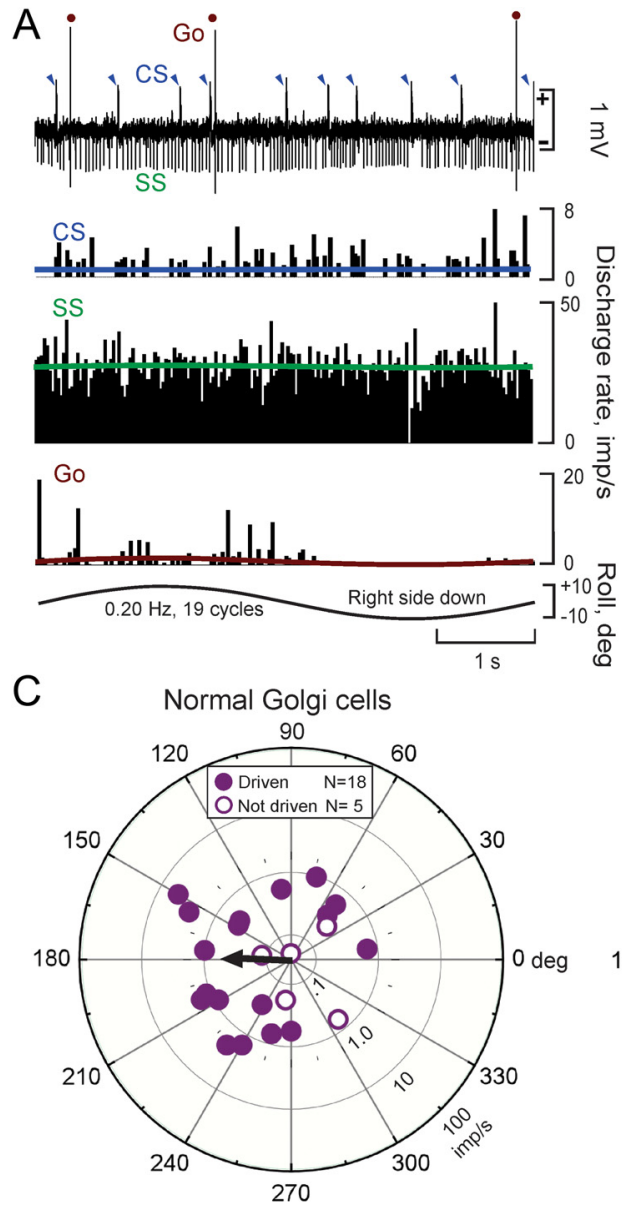

B
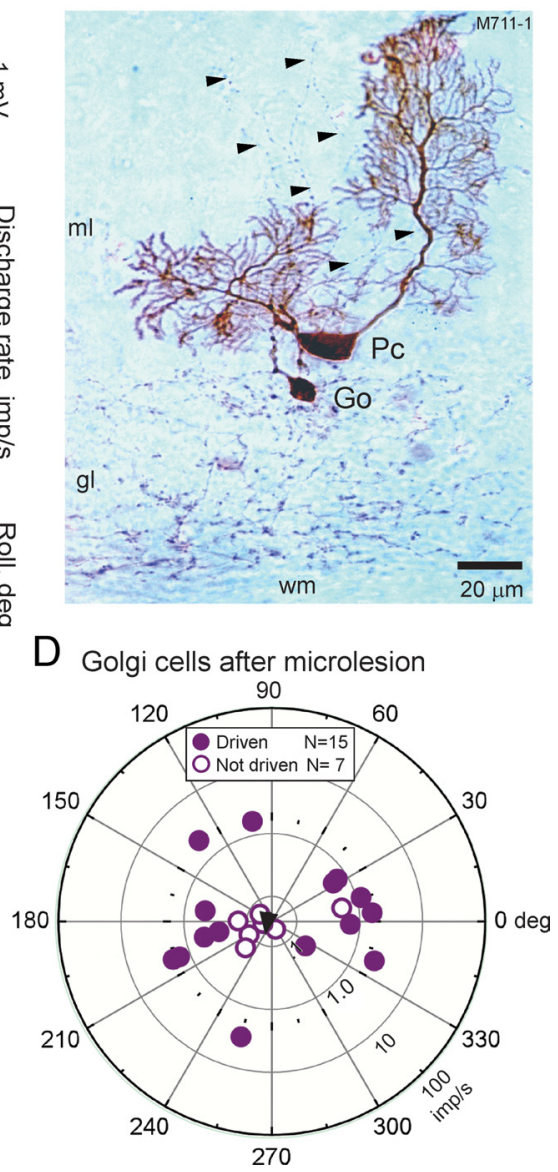

Figure 10. Vestibular modulation of Golgi cell activity is not reduced by olivary microlesions. Golgi cell activity evoked by vestibular stimulation was not reduced by microlesions of the contralateral $\beta$-nucleus and DMCC. $\boldsymbol{A}$, The electrophysiological record demonstrates that we recorded from a Golgi cell and a Purkinje cell in the left folium 9 in a mouse with a microlesion in the contralateral inferior olive. Golgi cell action potentials are indicated by brown circles. CSs are indicated by blue arrowheads. SSs are negative-going action potentials. Peristimulus histograms are shown for CSs (second trace), SSs (third trace), and Golgi cell (fourth trace). Each peristimulus histogram was fitted with a cosine function. The Golgi cell was responsive to ipsilateral roll-tilt. $\boldsymbol{B}$, The juxtacellularly labeled Golgi $\left(G_{0}\right)$ and Purkinje cells (Pc) are shown. The black arrowheads demarcate the trajectory of the Golgi cell beaded dendrite in the molecular layer ( $\mathrm{ml})$. The beaded axons of the Golgi cell ramify over the full-length and width of the granule cell layer ( $\mathrm{gl}$ ), bounded by the white matter (wm). C, D, Polar plots illustrate responses of Golgi cells to vestibular roll-tilt in normal mice ( $\boldsymbol{C}$ ) and in mice with olivary microlesions $(\boldsymbol{D})$. The DM and phase were measured for each cell. If the cell was not modulated by vestibular stimulation, it was plotted as an open circle. If the cell was modulated, it was plotted as a filled circle. The resultant vectors for the two populations of Golgi cells are indicated by black arrows. The apparent difference in the two populations was not statistically significant.

\section{Model of climbing fiber modulation of SSs}

We summarize possible functions of vestibular climbing and mossy fibers in a schematic model in which multiple parallel fibers from a variety of vestibular end organs are represented by different colored lines (Fig. 12). Each parallel fiber makes synaptic contact with the same Purkinje cell and ends in a synaptic terminal that either excites the Purkinje cell dendrite (solid triangle) or is subthreshold (open triangles). The color blue represents a plane of vestibular excitation common to the climbing fiber input and a subset of the mossy fiber-granule cell-parallel fibers that are conjointly activated by rotation about the longitudinal axis at a specific head angle. Three conditions are illustrated: (1) low parallel fiber activity, (2) high parallel fiber activity, and (3) high parallel fiber activity after long-term depression (LTD). The climbing fiber input under all three conditions remains constant. In the first condition, one-half of the parallel fiber synapses on Purkinje cells are inactive or "silent," reducing spontaneous SSs and decreasing the modulation of SSs evoked by climbing fibers (Fig. 12A). In the second condition, increased mossy fiber-granule cell-parallel fiber activity increases spontaneous SS discharge. Consequently, the same climbing fiber signal induces greater depth of modulation of SSs (Fig. 12B). With increased parallel fiber activity, a conflict occurs between the subset of mossy fibers and climbing fiber-evoked stellate cell inhibition, reducing the depth of modulation of SSs (Fig. 12C). This persistent conflict could be resolved by LTD (Sakurai, 1987; Crépel and Jaillard, 1991; Linden and Connor, 1993; Narasimhan and Linden, 1996; Ito, 2002; Mapelli and D'Angelo, 2007; Dean et al., 2010). LTD reduces the synaptic efficacy of parallel fiber signals that occur conjunctively with CSs while maintaining excitability of disjunctive parallel fiber signals (Ekerot and Jörntell, 2001; Jörntell and Ekerot, 2002). LTD could enhance the depth of modulation of SSs by minimizing the opposition between parallel fiber excitation and climbing fiber-evoked stellate cell inhibition.

\section{Discussion}

Loss of climbing fibers and reduced modulation of CSs, SSs, and stellate cell discharge

Two pertinent findings emerge from this experiment: First, blocking climbing fiber input to folia $8-10$ reduces vestibular modulation of both CSs and SSs. Second, olivary microlesions reduce vestibular modulation of stellate cells, but not granule cells, UBCs, or Golgi cells. These findings are consistent with three observations made in animals with intact inferior olives: (1) sinusoidal roll-tilt modulates the discharge of SSs $180^{\circ}$ out of phase with the discharge of mossy fibers (Barmack and Shojaku, 1995; Fushiki and Barmack, 1997; Yakhnitsa and Barmack, 2006), suggesting that mossy fibers do not account for the discharge of SSs; (2) although folia 8-9a-c receive only sparse vestibular primary and secondary afferent mossy fiber projections, the discharge of SSs in these folia remains antiphasic with that of the CSs (Barmack and Yakhnitsa, 2003; Yakhnitsa and Barmack, 2006); and (3) although horizontal semicircular canal afferents account for $\sim 20 \%$ of vestibular primary afferent mossy fiber input to folia 9d and 10 (Maklad and Fritzsch, 2003), horizontal vestibular stimulation fails to modulate the discharge of either CSs or SSs in these folia (Fushiki and Barmack, 1997; Yakhnitsa and Barmack, 2006; Yakusheva et al., 2007).

\section{Multiple influences of climbing fibers on modulation of SSs}

The source of modulation of SSs in a single Purkinje cell is not restricted to the single climbing fiber that makes synaptic contact on the Purkinje cell. Electrical stimulation of the inferior olive evokes CSs in Purkinje cells and a subsequent pause of SSs (Bloe- 

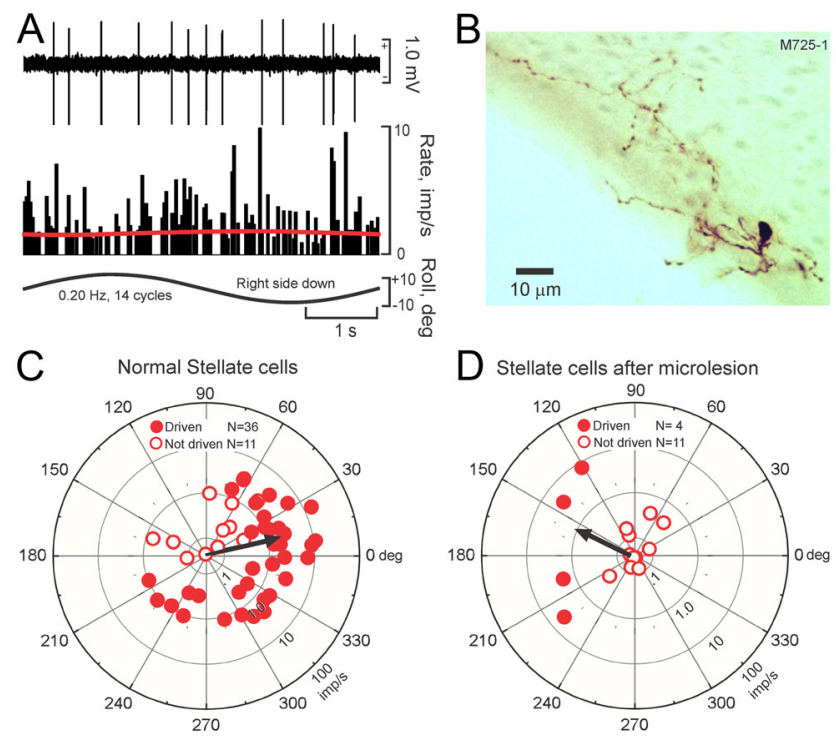

Figure 11. Vestibular modulation of stellate cells discharge is reduced by olivary microlesions. Stellate cell activity evoked by vestibular stimulation was significantly reduced by microlesions of the contralateral $\beta$-nucleus and DMCC. $A$, The activity of a stellate cell during sinusoidal roll-tilt i indicated. The peristimulus histogram was fitted with a cosine function (red line) indicating its insensitivity to roll-tilt. $\boldsymbol{B}, A$ juxtacellularly labeled stellate cell is shown. The recordings from this cell are presented in $\boldsymbol{A}$. C, D, Polar plots of stellate cell responses to vestibular roll-tilt are presented for normal mice $(\boldsymbol{C})$ and for mice with olivary microlesions (D). The DM and phase were measured for each cell. If the cell was not modulated by vestibular stimulation, it was plotted as an open circle. If the cell was modulated, it was plotted as a filled circle. The resultant vectors for the two populations of stellate cells are indicated by black arrows. The decreased numbers of responsive stellate cells in mice with olivary microlesions, the decrease in $\mathrm{DM}$, and the change in phase were significant.

del and Roberts, 1971). Pauses in SSs are still induced when the olivary stimulus is subthreshold for evoking a CS in the recorded Purkinje cell. This observation demonstrates that SS pauses are not simply a function of Purkinje cell-specific membrane conductance. Rather, pauses must be generated by inhibitory interneurons (or perhaps Bergmann astrocytes) activated by climbing fibers. Clearly, climbing fibers other than the one that evokes a CS in a particular Purkinje cell contribute to SS pauses. Conversely, the absence of a CS in a Purkinje cell does not indicate that all climbing fibers that influence the particular Purkinje cell are destroyed.

In mammals, stellate cells outnumber other cerebellar inhibitory interneurons_-Golgi cells, Lugaro cells, and basket cells_- by an order of magnitude and seem most likely to provide climbing fiberevoked modulation of SSs (Korbo et al., 1993). Stellate cells are excited by glutamate "spillover" from climbing fibers (Midtgaard, 1992; Szapiro and Barbour, 2007). They synapse upon the dendrites of Purkinje, Golgi, basket, and other stellate cells (Chan-Palay and Palay, 1972).

Another possible explanation for residual vestibular SS signals in the absence of CSs is that lesions of the inferior olive cause hypertrophy of Purkinje cell dendritic spines and an enhanced dendritic sensitivity to applied glutamate (Sotelo et al., 1975; Bravin et al., 1999). Possibly, the residual vestibular sensitivity of SSs in Purkinje cells lacking a climbing fiber input could be attributed to spines with enhanced sensitivity. This interpretation is consistent with our observation that six of the eight Purkinje cells with residual vestibular sensitivity of SSs were recorded from mice with chronic microlesions who survived at least $4 \mathrm{~d}$.

\section{Climbing and mossy fiber functions}

Climbing fiber discharge has two consequences. First, it directly evokes CSs in Purkinje cells arrayed in a sagittal zone. Second, it indirectly reduces SSs in Purkinje cells through its action on cerebellar inhibitory interneurons, most likely stellate cells. Paradoxically, the influence of inhibitory interneurons appears greater than that conveyed by vestibular primary afferent mossy fiber-granule cell-parallel fiber signals for the following three reasons: (1) mossy fiber-granule cell-parallel fiber signals are too diffuse to account for the specificity of SSs, (2) they have the wrong polarity to account for the phase of SSs evoked by vestibular stimulation, and (3) they are too weak to modulate SSs in the absence of modulated climbing fiber signals.

Mossy fibers convey a regionally topographic projection. Folia 9-10 receive vestibular primary afferent mossy fibers, not somatosensory mossy fibers from the arms, trunk, or legs. The abundance of granule cells may be necessary to distribute several vestibular end organ signals as widely as possible within folia 9-10 so that Purkinje cells receive a similar array of vestibular signals. Consequently, each Purkinje cell receives parallel fiber signals with contradictory information about head movement. Conversely, Purkinje cells within a climbing fiber zone receive restricted vestibular signals that specify a narrow range of head movements.

In the present experiment, when the climbing fiber signal was blocked, vestibular modulation of SSs and stellate cells was reduced. Molecular attempts to block stellate cell inhibition of Purkinje cells by knocking out the $\mathrm{GABA}_{\mathrm{A}} \gamma 2$ receptor subunit in Purkinje cells and thereby depleting Purkinje cells of $\mathrm{GABA}_{\mathrm{A}}$ receptors have yielded ambiguous results (Wulff et al., 2009). Knock-outs of a $\mathrm{GABA}_{\mathrm{A}}$ receptor subunit reduced, but did not eliminate climbing fiber-evoked pauses in SSs. Floccular Purkinje cells still retained some antiphasic modulation of SSs by optokinetically evoked CSs. Possibly the knock-out was incomplete, or compensated by other cellular and/or molecular mechanisms such as climbing fiber-activated $\mathrm{Ca}^{2+}$-dependent $\mathrm{K}^{+}$channels, Golgi cell inhibition (see below), or LTD.

Climbing fiber-activated $\mathrm{Ca}^{2+}$-dependent $\mathrm{K}^{+}$channels in Purkinje cells account for pauses in SSs measured in vitro (McKay et al., 2007) even when GABAergic transmission by stellate cells is blocked by bath-applied picrotoxin. However, as mentioned above, all pauses are not alike. Pauses that are observed in vivo can be evoked by olivary stimuli subthreshold for the Purkinje cells in which they are observed. Pauses that are evoked in vitro appear to be prevalent in a preparation that regularly oscillates between states of spontaneous activity and total silence, often classified as "bistable." In our in vivo preparation, this condition of "bistability" is rare and indicative of damage to the cerebellar cortex.

LTD by itself cannot account for antiphasic regulation of SSs by CSs. LTD can be blocked by a knocked-in expression of a protein kinase C inhibitor (Goossens et al., 2004). In such mice, antiphasic modulation of CSs and SSs is preserved. One of the ways that LTD could contribute to the antiphasic discharge of CSs and SSs in unimpaired cerebellar circuitry is discussed below.

\section{Golgi cells and incomplete unilateral microlesions of the $\boldsymbol{\beta}$-nucleus and DMCC}

Although the differences between vestibularly evoked Golgi cell discharge in normal mice and mice with microlesions failed to attain statistical significance, we cannot discount the possibility that Golgi cells are influenced by both climbing fibers and stellate cells. Golgi cells are the only cerebellar interneurons onto which 

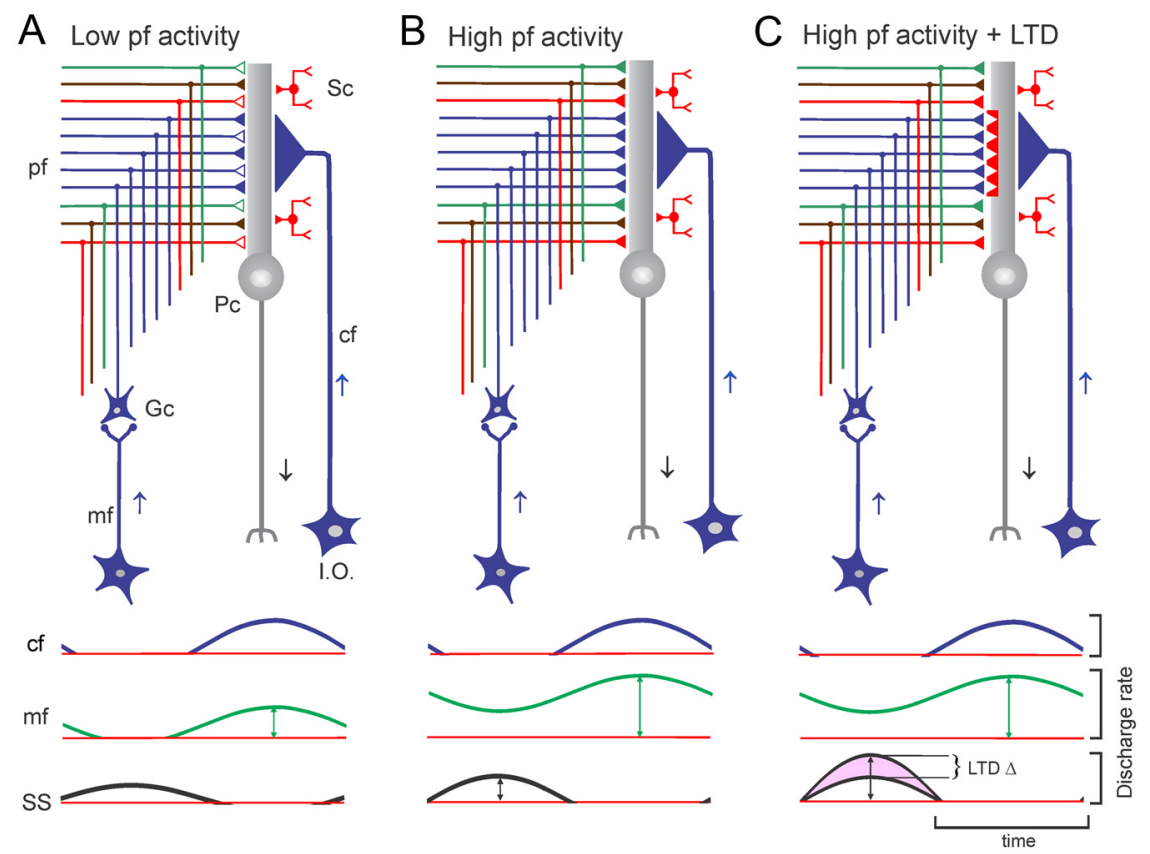

Figure 12. Mossy fiber gain control of climbing fiber-evoked SS modulation. We assume that the effectiveness of climbing fiber-evoked stellate cell inhibition of SSs depends on both climbing fiber and parallel fiber activity. We show parallel fibers of different colors that synapse on a Purkinje cell. A subset of mossy fiber-granule cell-parallel fibers (blue lines) corresponds to vestibular primary afferents that discharge in phase with a vestibular climbing fiber (blue). Below the anatomical schematics, a sinusoidally modulated climbing fiber signal is represented in the top horizontal trace in all three panels. Its amplitude remains constant in all three conditions $(\boldsymbol{A}-\boldsymbol{C})$. $\boldsymbol{A}$, Climbing fiber-evoked modulation of SSs is achieved through stellate cell inhibition of Purkinje cells. The middle trace indicates a low steady-state activity of the mossy fiber signal (dashed, blue line) that reduces parallel fiber excitation of Purkinje cells (open parallel fiber terminals). The lower level of parallel fiber excitation of the Purkinje cell reduces the modulated discharge of SSs (lower trace) by climbing fiber-evoked stellate cell inhibition. The red lines indicate a discharge rate of $0 \mathrm{imp} / \mathrm{s} . \boldsymbol{B}$, Increased mossy fiber spontaneous activity (middle trace) evokes greater parallel fiber excitation of the Purkinje (filled parallel fiber terminals). Hence a constant climbing fiber signal evokes a greater modulation of SSs (bottom trace). C, Modulation of SSs is increased during LTD, by reducing the synaptic efficacy of parallel fibers that discharge in phase with the climbing fiber signal. Without LTD, SS modulation is reduced by a conflict between climbing fiber-evoked stellate cell inhibition of the Purkinje cell and parallel fiber excitation. However, during LTD the conjunctive discharge of climbing and parallel fibers causes decreased synaptic efficacy of parallel fibers (black bar on Purkinje cell). LTD enhances the modulation of SSs by reducing the conflict between in-phase climbing fiber and parallel fiber signals. The increment in modulation attributed to LTD is indicated in pink. Abbreviations: cf, Climbing fiber; Gc, granule cell; I.O., inferior olive; mf, mossy fiber; Pc, Purkinje cell; pf, parallel fiber; Sc, stellate cell.

climbing fibers make a synapse (Hámori and Szentágothai, 1966, 1980; Desclin, 1976; Sugihara et al., 1999). Stellate cells synapse upon Golgi cell dendrites (Chan-Palay and Palay, 1972). This could allow climbing fiber signals to influence the activity of large numbers of granule cells and UBCs (Dugué et al., 2005). Climbing fibers could also indirectly influence the modulation of Golgi cells through stellate cell inhibition. In normal mice, Golgi cells discharge out of phase with climbing and mossy fibers and in phase with SSs (Fig. 10C). Consequently, in normal mice Golgi cells are unlikely to modulate the antiphasic discharge of CSs and SSs. In mice with olivary microlesions, nearly one-half of the Golgi cells discharged in phase with residual climbing and mossy fibers. This could result from the loss of climbing fiber-evoked stellate cell inhibition of Golgi cells. If so, Golgi cells could preserve antiphasic discharge of SSs by inhibiting the activity of a targeted population of granule cells and UBCs.

Several groups have characterized the discharge of Golgi cells in normal animals (Vos et al., 1999; Simpson et al., 2005; Holtzman et al., 2006b; Barmack and Yakhnitsa, 2008a). Without exception, they agree that Golgi cells discharge at frequencies $<10 \mathrm{imp} / \mathrm{s}$. However, we recorded from three Golgi cells whose discharges exceeded $40 \mathrm{imp} / \mathrm{s}$, suggesting that the loss of climbing fibers may influence Golgi cell discharge, possibly mediated through the loss of stellate cell inhibition.

\section{Generality of climbing fiber-induced modulation of SSs}

The uvula-nodulus is structurally ideal to test the functional independence of CSs and SSs since the anatomical pathways by which vestibular climbing fibers and primary vestibular afferent mossy fibers reach the cerebellum are anatomically distinct, accessible, and oppositely lateralized. In other cerebellar systems, the origins and modalities of mossy fibers is more complex. In the flocculus, horizontal optokinetic stimulation is effective in modulating the activity of climbing fibers that originate from the contralateral inferior olive (Maekawa and Simpson, 1973; Alley et al., 1975; Graf et al., 1988; Takeda and Maekawa, 1989; Barmack and Shojaku, 1995). However, the origins of mossy fiber projections are more varied than in the uvula-nodulus. Consequently, it may be more difficult to evaluate whether one of several populations of mossy fibers contribute to the modulation of SSs in the flocculus. However, floccular Purkinje cells evince the same antiphasic responses between CSs and SSs as do Purkinje cells in the uvula-nodulus (Kobayashi et al., 1998; Goossens et al., 2004).

Although departures from antiphasic discharge of floccular Purkinje cell CSs and SSs have been reported (Leonard and Simpson, 1986; Powell et al., 1996), these examples merely confirm that modulation of SSs in a particular Purkinje cell may be independent of the CS in the same Purkinje cell. Horizontal optokinetic and vestibular modulation of SSs in a floccular Purkinje cell may be influenced by several climbing fibers that project to adjacent Purkinje cells and activate common interneuronal circuitry.

In the nodulus, climbing fiber-evoked modulation of SSs depends on the location of the Purkinje cell within a climbing fiber zone. The depth of modulation of SSs is approximately five times greater for Purkinje cells located at the center of a zone compared with the depth of modulation of SSs in Purkinje cells located in a zonal periphery (Fushiki and Barmack, 1997). It is necessary to know the exact location of a recording electrode within a climbing fiber zone to interpret the antiphasic behavior of CSs and SSs.

Climbing fibers are the primary sensory input that controls the discharge of both CSs and SSs in cerebellar Purkinje cells. Climbing fiber-evoked stellate cell inhibition of Purkinje cells provides a major synaptic mechanism by which the antiphasic discharges of CSs and SSs are regulated. While this evidence contradicts accepted views of cerebellar circuitry, it expands our conceptual view of how the cerebellum contributes to the control of movement. The relative contributions of stellate cells, Golgi cells, 
and possibly even LTD to the modulation of Purkinje cell discharge can be resolved by additional experiments.

\section{References}

Alley K, Baker R, Simpson JI (1975) Afferents to the vestibulo-cerebellum and the origin of the visual climbing fibers in the rabbit. Brain Res 98:582-589.

Apps R, Garwicz M (2005) Anatomical and physiological foundations of cerebellar information processing. Nat Rev Neurosci 6:297-311.

Armstrong DM, Edgley SA (1988) Discharges of interpositus and Purkinje cells of the cat cerebellum during locomotion under different conditions. J Physiol 400:425-445.

Barmack NH, Shojaku H (1995) Vestibular and visual signals evoked in the uvula-nodulus of the rabbit cerebellum by natural stimulation. J Neurophysiol 74:2573-2589.

Barmack NH, Yakhnitsa V (2003) Cerebellar climbing fibers modulate simple spikes in cerebellar Purkinje cells. J Neurosci 23:7904-7916.

Barmack NH, Yakhnitsa V (2008a) Functions of interneurons in mouse cerebellum. J Neurosci 28:1140-1152.

Barmack NH, Yakhnitsa V (2008b) Distribution of granule cells projecting to focal Purkinje cells in mouse uvula-nodulus. Neuroscience 156:216-221.

Bloedel JR, Bracha V (2009) Cerebellar functions. In: Encyclopedic reference of neuroscience (Binder MD, Hirokawa N, Windhorst U, eds), pp 667-671. Heidelberg: Springer.

Bloedel JR, Roberts WJ (1971) Action of climbing fibers in cerebellar cortex of the cat. J Neurophysiol 34:17-31.

Brand S, Dahl AL, Mugnaini E (1976) The length of parallel fibers in the cat cerebellar cortex. An experimental light and electron microscopic study. Exp Brain Res 26:39-58.

Bravin M, Morando L, Vercelli A, Rossi F, Strata P (1999) Control of spine formation by electrical activity in the adult rat cerebellum. Proc Natl Acad Sci U S A 96:1704-1709.

Chan-Palay V, Palay SL (1972) The stellate cells of the rat's cerebellar cortex. Z Anat Entwicklungsgesch 136:224-248.

Crépel F, Jaillard D (1991) Pairing of pre- and postsynaptic activities in cerebellar Purkinje cells induces long-term changes in synaptic efficacy in vitro. J Physiol 432:123-141.

Dean P, Porrill J, Ekerot CF, Jörntell H (2010) The cerebellar microcircuit as an adaptive filter: experimental and computational evidence. Nat Rev Neurosci 11:30-43.

Desclin JC (1976) Early terminal degeneration of cerebellar climbing fibers after destruction of the inferior olive in the rat. Synaptic relationships in the molecular layer. Anat Embryol (Berl) 149:87-112.

Dugué GP, Dumoulin A, Triller A, Dieudonné S (2005) Target-dependent use of coreleased inhibitory transmitters at central synapses. J Neurosci 25:6490-6498.

Ebner TJ, Bloedel JR (1981) Role of climbing fiber afferent input in determining responsiveness of Purkinje cells to mossy fiber inputs. J Neurophysiol 45:962-971.

Eccles JC, Llinás R, Sasaki K (1966) The excitatory synaptic action of climbing fibers on the Purkinje cells of the cerebellum. J Physiol 182:268-296.

Ekerot CF, Jörntell H (2001) Parallel fibre receptive fields of Purkinje cells and interneurons are climbing fibre-specific. Eur J Neurosci 13:1303-1310.

Fox CA, Hillman DE, Siegesmund KA, Dutta CR (1967) The primate cerebellar cortex: a Golgi and electron microscopic study. In: Progress in brain research, Vol 25, The cerebellum (Fox CA, Snider RS, eds), pp 174-225. New York: Elsevier.

Fushiki H, Barmack NH (1997) Topography and reciprocal activity of cerebellar Purkinje cells in the uvula-nodulus modulated by vestibular stimulation. J Neurophysiol 78:3083-3094.

Ghez C, Thach WT (2000) The cerebellum. In: Principles of neuroscience (Kandel ER, Schwartz J, Jessel TM, eds), pp 832-852. New York: Elsevier.

Goossens HH, Hoebeek FE, Van Alphen AM, Van Der Steen J, Stahl JS, De Zeeuw CI, Frens MA (2004) Simple spike and complex spike activity of floccular Purkinje cells during the optokinetic reflex in mice lacking cerebellar long-term depression. Eur J Neurosci 19:687-697.

Graf W, Simpson JI, Leonard CS (1988) Spatial organization of visual messages of the rabbit's cerebellar flocculus. II. Complex and simple spike responses of Purkinje cells. J Neurophysiol 60:2091-2121.

Granit R, Phillips CG (1956) Excitatory and inhibitory processes acting upon individual Purkinje cells of the cerebellum in cats. J Physiol 133:520-547.

Hámori J, Szentágothai J (1966) Participation of Golgi neuron processes in the cerebellar glomeruli: an electron microscope study. Exp Brain Res 2:35-48.

Hámori J, Szentágothai J (1980) Lack of evidence of synaptic contacts by climbing fibre collaterals to basket and stellate cells in developing rat cerebellar cortex. Brain Res 186:454-457.

Harvey RJ, Napper RM (1991) Quantitative studies on the mammalian cerebellum. Prog Neurobiol 36:437-463.

Holtzman T, Rajapaksa T, Mostofi A, Edgley SA (2006a) Different responses of rat cerebellar Purkinje cells and Golgi cells evoked by widespread convergent sensory inputs. J Physiol 574:491-507.

Holtzman T, Mostofi A, Phuah CL, Edgley SA (2006b) Cerebellar Golgi cells in the rat receive multimodal convergent peripheral inputs via the lateral funiculus of the spinal cord. J Physiol 577:69-80.

Horn KM, Pong M, Gibson AR (2010) Functional relations of cerebellar modules of the cat. J Neurosci 30:9411-9423.

Ito $M$ (2002) The molecular organization of cerebellar long-term depression. Nat Rev Neurosci 3:896-902.

Jörntell H, Ekerot CF (2002) Reciprocal bidirectional plasticity of parallel fiber receptive fields in cerebellar Purkinje cells and their afferent interneurons. Neuron 34:797-806.

Kano M, Kano MS, Maekawa K (1991) Simple spike modulation of Purkinje cells in the cerebellar nodulus of the pigmented rabbit to optokinetic stimulation. Neurosci Lett 128:101-104.

Kobayashi Y, Kawano K, Takemura A, Inoue Y, Kitama T, Gomi H, Kawato M (1998) Temporal firing patterns of Purkinje cells in the cerebellar ventral paraflocculus during ocular following responses in monkeys. II. Complex spikes. J Neurophysiol 80:832-848.

Korbo L, Andersen BB, Ladefoged O, Møller A (1993) Total numbers of various cell types in rat cerebellar cortex estimated using an unbiased stereological method. Brain Res 609:262-268.

Leonard CS, Simpson JI (1986) Simple spike modulation of floccular Purkinje cells during reversible blockade of their climbing fiber afferents. In: Adaptive processes in visual and oculomotor systems (Keller E, Zee D, eds), pp 429-434. Oxford, UK: Pergamon.

Linden DJ, Connor JA (1993) Cellular mechanisms of long-term depression in the cerebellum. Curr Opin Neurobiol 3:401-406.

Lisberger SG, Pavelko TA, Bronte-Stewart HM, Stone LS (1994) Neural basis for motor learning in the vestibuloocular reflex of primates. II. Changes in the responses of horizontal gaze velocity Purkinje cells in the cerebellar flocculus and ventral paraflocculus. J Neurophysiol 72:954-973.

Maekawa K, Simpson JL (1973) Climbing fiber responses evoked in vestibulocerebellum of rabbit from visual system. J Neurophysiol 36:649-666.

Maklad A, Fritzsch B (2003) Partial segregation of posterior crista and saccular fibers to the nodulus and uvula of the cerebellum in mice, and its development. Brain Res Dev Brain Res 140:223-236.

Mapelli J, D'Angelo E (2007) The spatial organization of long-term synaptic plasticity at the input stage of cerebellum. J Neurosci 27:1285-1296.

McKay BE, Engbers JD, Mehaffey WH, Gordon GR, Molineux ML, Bains JS, Turner RW (2007) Climbing fiber discharge regulates cerebellar functions by controlling the intrinsic characteristics of Purkinje cell output. J Neurophysiol 97:2590-2604.

Midtgaard J (1992) Stellate cell inhibition of Purkinje cells in the turtle cerebellum in vitro. J Physiol 457:355-367.

Nagao S (1989) Role of cerebellar flocculus in adaptive interaction between optokinetic eye movement response and vestibulo-ocular reflex in pigmented rabbits. Exp Brain Res 77:541-551.

Narasimhan K, Linden DJ (1996) Defining a minimal computational unit for cerebellar long-term depression. Neuron 17:333-341.

Olucha F, Martínez-García F, López-García C (1985) A new stabilizing agent for the tetramethyl benzidine (TMB) reaction product in the histochemical detection of horseradish peroxidase (HRP). J Neurosci Methods 13:131-138.

Palkovits M, Magyar P, Szentágothai J (1972) Quantitative histological analysis of the cerebellar cortex in the cat. IV. Mossy fiber-Purkinje cell numerical transfer. Brain Res 45:15-29.

Pinault D (1996) A novel single-cell staining procedure performed in vivo under electrophysiological control: morpho-functional features of juxta- 
cellularly labeled thalamic cells and other central neurons with biocytin or Neurobiotin. J Neurosci Methods 65:113-136.

Powell KD, Quinn KJ, Peterson BW, Baker JF (1996) Preferred axis of rotation of floccular Purkinje cells in the decerebrate cat. Brain Res 710:281-286.

Rye DB, Saper CB, Wainer BH (1984) Stabilization of tetramethylbenzidine (TMB) reaction product: application of retrograde and anterograde tracing, and combination with immunohistochemistry. J Histochem Cytochem 32:1145-1153.

Sakurai M (1987) Synaptic modification of parallel fibre-Purkinje cell transmission in in vitro guinea-pig cerebellar slices. J Physiol 394:463-480.

Schor RH, Miller AD, Tomko DL (1984) Responses to head tilt in cat central vestibular neurons. I. Direction of maximum sensitivity. J Neurophysiol 51:136-146.

Simpson JI, Hulscher HC, Sabel-Goedknegt E, Ruigrok TJ (2005) Between in and out: linking morphology and physiology of cerebellar cortical interneurons. Prog Brain Res 148:329-340.

Sotelo C, Hillman DE, Zamora AJ, Llinás R (1975) Climbing fiber deafferentation: its action on Purkinje cell dendritic spines. Brain Res 98:574-581.

Sugihara I, Wu H, Shinoda Y (1999) Morphology of single olivocerebellar axons labeled with biotinylated dextran amine in the rat. J Comp Neurol 414:131-148.

Szapiro G, Barbour B (2007) Multiple climbing fibers signal to molecular layer interneurons exclusively via glutamate spillover. Nat Neurosci 10:735-742.

Takeda T, Maekawa K (1989) Olivary branching projections to the flocculus, nodulus and uvula in the rabbit. II. Retrograde double labeling study with fluorescent dyes. Exp Brain Res 76:323-332.

Thach WT (1970) Discharge of cerebellar neurons related to two maintained postures and two prompt movements. II. Purkinje cell output and input. J Neurophysiol 33:537-547.

Vos BP, Volny-Luraghi A, De Schutter E (1999) Cerebellar Golgi cells in the rat: receptive fields and timing of responses to facial stimulation. Eur J Neurosci 11:2621-2634

Walter JT, Khodakhah K (2006) The linear computational algorithm of cerebellar Purkinje cells. J Neurosci 26:12861-12872.

Wulff P, Schonewille M, Renzi M, Viltono L, Sassoe-Pognetto M, Badura A, Gao Z, Hoebeek FE, van Dorp S, Wisden W, Farrant M, De Zeeuw CI (2009) Synaptic inhibition of Purkinje cells mediates consolidation of vestibulo-cerebellar motor learning. Nat Neurosci 12:1042-1049.

Yakhnitsa V, Barmack NH (2006) Antiphasic Purkinje cell responses in mouse uvula-nodulus are sensitive to static roll-tilt and topographically organized. Neuroscience 143:615-626.

Yakusheva TA, Shaikh AG, Green AM, Blazquez PM, Dickman JD, Angelaki DE (2007) Purkinje cells in posterior cerebellar vermis encode motion in an inertial reference frame. Neuron 54:973-985.

Zar JH (1984) Biostatistical analysis. Englewood Cliffs, NJ: Prentice Hall. 